\title{
Dinâmica do nível freático e da salinização das águas subterrâneas em áreas irrigadas ${ }^{1}$
}

\author{
Eunice Maia de Andrade ${ }^{2 *}$, Deodato do Nascimento Aquino ${ }^{2}$, Nayara Rochelli de Sousa Luna ${ }^{3}$, \\ Fernando Bezerra Lopes ${ }^{4}$, Lindbergue de Araújo Crisóstomo ${ }^{5}$
}

$10.1590 / 0034-737 X 201663050005$

\section{RESUMO}

Análises físicas e hidroquímicas foram realizadas, em poços rasos, com o objetivo de identificar os impactos da irrigação e da sazonalidade climática no processo de salinização e na dinâmica do nível das águas subterrâneas do Distrito Irrigado do Baixo Acaraú - DIBAU, Ceará. As amostragens foram realizadas em dois períodos: dez/2003 a maio/ 2007; agosto/2010 a julho/2011, em cinco poços rasos (P1, P2, P3, P4, P5), sendo três deles em campos irrigados. Na identificação da similaridade ou dissimilaridade dos teores de íons sódio $\left(\mathrm{Na}^{+}\right)$, cloreto $\left(\mathrm{Cl}^{-}\right)$e nitrato $\left(\mathrm{NO}_{3}^{-}\right)$entre as duas épocas estudadas, bem como entre os poços amostrados, aplicou-se a técnica de análise estatística multivariada de agrupamento hierárquico. Os dados médios foram submetidos à análise de teste de média e confrontados pelo Teste T. As águas dos poços inseridos na área de sequeiro apresentaram as maiores concentrações médias de $\mathrm{Na}^{+}$e $\mathrm{Cl}^{-}, 123 \mathrm{mg}$ $\mathrm{L}^{-1}$ e 253,2 $\mathrm{mg} \mathrm{L}^{-1}$, respectivamente, enquanto os valores médios de $\mathrm{NO}_{3}^{-}$foram maiores na área irrigada, $16 \mathrm{mg} \mathrm{L}^{-1}$. Identificou-se elevação do nível do lençol freático nos poços inseridos na área irrigada (P3, P4 e P5) de 6,13; 5,25 e 3,40 $\mathrm{m}$, respectivamente. As menores flutuações sazonais do lençol freático ocorreram nos poços inseridos na área irrigada, mostrando excedentes de lâminas de irrigação e recarga desses poços, durante a estação seca. As concentrações de $\mathrm{Na}^{+}$ e de $\mathrm{Cl}^{-}$, nas águas do lençol freático, são determinadas pelos fatores naturais, diferentemente do que ocorre com as do $\mathrm{NO}_{3}$.

Palavras-chave: irrigação, contaminação, água subterrânea, nitrato.

\section{ABSTRACT}

\section{Dynamics of water table level and groundwater salinity at an irrigated field}

Physical and hydro chemical analysis were carried out in shallow wells with the objective of identifying the impact of irrigation and of the climatic seasonality in the process of salinization and in dynamic of the groundwater level of the Distrito Irrigado do Baixo Acaraú - DIBAU, Ceará. The samples were taken in two periods: Dec/2003 to May/2007 and Aug/2010 to July/2011 in five shallow wells (P1, P2, P3, P4, P5), three being inserted into irrigated fields. In identifying the similarities or dissimilarities of the sodium $\left(\mathrm{Na}^{+}\right)$, chlorine $(\mathrm{Cl})$ and nitrate $\left(\mathrm{NO}_{3}^{-}\right)$ions between the two studied time periods and between the sampled wells, statistical multivariate analysis of hierarchical cluster analysis was applied. The average data were submitted to the average test and confronted through the t-test. The waters of the unirrigated fields presented the highest average concentrations of $\mathrm{Na}^{+}$and $\mathrm{Cl}^{-}, 123 \mathrm{mg} \mathrm{L}^{-1}$ and $253.2 \mathrm{mg} \mathrm{L}^{-1}$, respectively, while the highest average values of $\mathrm{NO}_{3}^{-}\left(16 \mathrm{mg} \mathrm{L}^{-1}\right)$ were found in the irrigated area. An elevation of the level of the water table

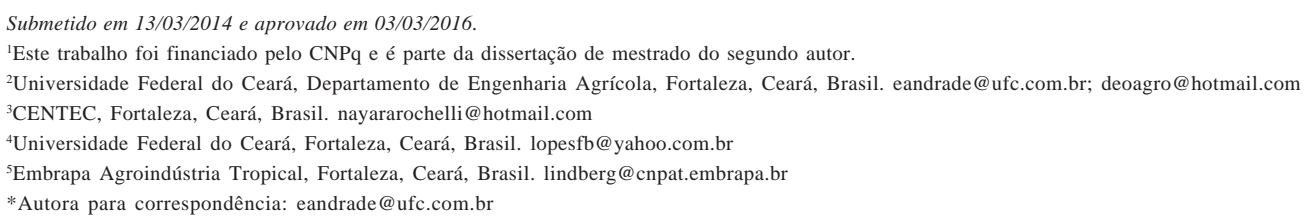


was identified in the wells inserted in the irrigated area (P3, P4 and P5) of 6.13; 5.25 and $3.40 \mathrm{~m}$, respectively. The smallest seasonal fluctuations of the water table occurred in the irrigated area wells, showing an excess of irrigation water, which upper the groundwater level during the dry season. The concentrations of $\mathrm{Na}^{+}$and $\mathrm{Cl}^{-}$in the groundwaters are determined by natural factors, differently from the $\mathrm{NO}_{3}$.

Key words: irrigation, contamination, groundwater, nitrate.

\section{INTRODUÇÃO}

Através dos séculos, a complexidade dos usos múltiplos da água pelo homem aumentou, desencadeando degradação e poluição (Chen et al., 2010; Baba \& Tayfur, 2011), acarretadas pela pressão de uso imposta pelo crescimento demográfico, pelo aumento das áreas incorporadas à agricultura irrigada (Feng et al., 2005; Withers et al., 2012) e pela instalação de complexos industriais, dentre outras causas (Tundisi, 2003).

Neste início de século, presencia-se uma preocupação sem precedentes com a escassez de água potável para a demanda da população mundial. Se o problema de quantidade já é preocupante, o da qualidade é ainda maior (Palácio et al., 2008; Scanlon et al., 2010). Por essa razão, tem-se o consenso de que as águas subterrâneas correspondem a uma fonte cada vez mais importante para atender à demanda humana, na medida em que, progressivamente, outras fontes de abastecimento superficiais se tornam escassas. As águas subterrâneas desempenham papel mais abrangente, além de sua viabilidade de uso para fins de abastecimentos doméstico, industrial e na agricultura, elas podem também fornecer informações sobre a natureza dos solos e das rochas por onde percolam (Araújo, 2005).

A contaminação das águas subterrâneas por atividades antrópicas, principalmente nas regiões semiáridas, vem resultando no abandono de muitos poços ou na perda de áreas importantes dos mananciais hídricos (Oster, 2006). Por causa dos fatores climáticos e das condições edáficas das regiões semiáridas, uma das ações antrópicas que mais contribuem para a contaminação das águas subterrâneas é a prática da irrigação.

Embora a irrigação seja um importante fator que contribui para a segurança alimentar e o desenvolvimento econômico de muitas regiões, principalmente as áridas e semiáridas, se não manejada adequadamente poderá acarretar danos irreversíveis ao solo e comprometer a qualidade da água nessas regiões, nas quais a escassez deste recurso já tem sido notória (Manning et al., 2005; Moore et al., 2006; Aquino et al., 2008; Andrade et al., 2009). A implementação de perímetros de irrigação, associada ao regime irregular das chuvas e às elevadas taxas de evapotranspiração nas regiões semiáridas, tende a causar alterações dos teores de sais dos solos e das águas, com os consequentes aumentos da concentração de íons tóxicos e elevação do nível do lençol freático (Osenbrück et al., 2006).

No campo da influência das atividades antrópicas na qualidade das águas, a agricultura irrigada é tida como a principal consumidora e uma das principais poluidoras dos recursos hídricos, sendo a salinidade e a contaminação por nitrato os principais indicadores de poluição das águas subterrâneas (Brown et al., 2000; Ersahin \& Karaman, 2001; Andrade et al., 2008).

Khaw \& Barrett (1987) afirmam que o alto consumo humano de sódio em geral se acompanha de baixo consumo de potássio, sendo que a ingestão diária recomendada de potássio tem efeito protetor na redução da ocorrência de mortalidade por AVC (Acidente Cárdio Vascular). Dentre as variáveis estudadas e que se associam à alta prevalência de hipertensão arterial, está o alto consumo de água com teores elevados de sódio. A hipertensão arterial é um dos mais importantes fatores de risco que levam ao desenvolvimento de acidente vascular cerebral e ao infarto do miocárdio (Molina et al., 2003).

A ingestão de nitrato por meio das águas de abastecimento representa um potencial de risco para a saúde, pois pode causar a meta-hemoglobinemia ("síndrome do bebêazul") em recém-nascidos e, mesmo, em adultos com particular deficiência enzimática. A síndrome do bebê-azul ocorre porque o nitrito oxida os íons ferrosos da hemoglobina a íons férricos, gerando a meta-hemoglobina, que é menos eficiente na absorção e transferência de oxigênio para as células e favorece a formação potencial de nitrosaminas e nitrosamidas carcinogênicas, dois efeitos adversos à saúde, potencializadores do aparecimento de células cancerígenas (Alaburda \& Nishihara, 1998; Ramos et al., 2006).

Por essa razão, objetivou-se, com este trabalho, determinar o impacto da irrigação e da sazonalidade climática na qualidade das águas subterrâneas rasas e nas alterações do regime de flutuação do nível do lençol freático, em regiões semiáridas, nas quais a evapotranspiração é aproximadamente o dobro da lâmina precipitada. 


\section{MATERIAL E MÉTODOS}

O Distrito de Irrigação do Baixo Acaraú - DIBAU está situado no divisor topográfico de duas bacias hidrográficas, a do rio Acaraú e a Bacia Litorânea. A bacia do Acaraú é drenada pelo rio de mesmo nome, o qual nasce na Serra da Mata, em cotas superiores a $800 \mathrm{~m}$, e desenvolve-se no sentido sul-norte, com aproximadamente $315 \mathrm{~km}$ de extensão (Figura 1). O DIBAU tem uma área irrigável de aproximadamente 12.656 mil hectares, dos quais, em 2013, apenas 4000 hectares se contavam efetivamente com projeto de irrigação.

A granulometria do solo da região é variada, constituída por sedimentos arenosos e areno-argilosos, às vezes intercalados com camadas de cascalhos de quartzo desarestado e concentrações lateríticas em maiores profundidades. Geralmente, essas formações originam solos profundos e de textura arenosa (Matias Filho et al., 2001). Por serem solos arenosos, com predominância de macroporos, a taxa de infiltração é elevada e ocorre uma drenagem livre da água em profundidades inferiores a dois metros (Aquino et al., 2008).

A partir de sobreposição da carta de solo da região na qual se localiza o DIBAU, com o uso do Arcview 3.2, Alves (2006) identificou e atualizou todas as classes de solos pertencentes ao distrito de irrigação, segundo a classificação proposta pela Embrapa (2013). Os resultados apresentados destacam a predominância de manchas de Argissolos Vermelho-Amarelo eutrófico, Argissolos Acinzentado distrófico e Neossolos Regolíticos.

De acordo com a classificação de Köppen (1918), o clima da área de estudo é do tipo Aw', quente e úmido com chuvas de verão-outono, registrando temperaturas médias mensais superiores a $18^{\circ} \mathrm{C}$, com amplitude térmica inferior a $5{ }^{\circ} \mathrm{C}$, sendo os meses de novembro e dezembro os mais quentes do ano. A região apresenta precipitação anual média de 960 mm e evaporação potencial de aproximadamente $1600 \mathrm{~mm}$ anuais.

Nesta pesquisa, foram estabelecidas como variáveis a dinâmica temporal do nível das águas do lençol freático e os parâmetros químicos Sódio $\left(\mathrm{Na}^{+}\right)$, Cloreto $\left(\mathrm{Cl}^{-}\right)$e Nitrato $\left(\mathrm{NO}_{3}^{-}\right)$, da água de cinco poços rasos que foram monitorados em dois períodos distintos. No Período 1, contabilizaram-se esses atributos durante 27 meses (dezembro/2003 a novembro/2005, novembro/2006 e maio de 2007); no Período 2, contabilizaram-se durante 12 meses (agosto/10 a julho/11), totalizando 780 análises (39 meses x 5 poços x 4 atributos). Os pontos foram selecionados tomando-se por base a maior representatividade de toda a área em estudo (Figura 1).

Em todos os pontos de monitoramento, as águas são utilizadas pela população local para consumo. Todos os poços foram georreferenciados e numerados de 1 a 5 , tomando-se então a nomenclatura de Poços $(\mathrm{P})$, seguida do número correspondente. Nas áreas dos poços P1, P2 e P5, no período 1, não se praticava agricultura irrigada; enquanto os poços P3, P4 e P5, no período 2, estavam inseridos em campos irrigados, sendo que constituiam área irrigada desde o ano de 2001. A área do P5 passou a ser irrigada somente a partir de meados de 2008.

Para as análises químicas, foram coletadas amostras de água em recipientes plásticos com volume de $1 \mathrm{~L}$, sendo adicionado $1 \mathrm{~mL}$ de tolueno, a fim de preservar o estado natural das amostras. No momento da coleta das águas, era realizada uma tríplice lavagem do recipiente, com o propósito de diminuir a interferência de qualquer resíduo ou remanescente de coletas anteriores. As análises hidroquímicas das variáveis estudadas foram efetivadas de acordo com a metodologia descrita por Richards (1954).

Para a classificação, quanto à similaridade, das águas amostradas, quanto aos íons estudados, utilizou-se a análise de agrupamento hierárquica, com o software SPSS 16.0. $\mathrm{Na}$ tentativa de se evitarem os erros devidos às escalas e às unidades, os dados foram normalizados $(\mathrm{x}=0, \sigma=1)$, pela seguinte relação:

$Y_{i j}=\frac{X_{i j}-\bar{X}_{i}}{S_{i}}$,em que

$X_{\mathrm{ij}}$ representa o valor da j-ésima observação da i-ésima variável, $\mathrm{X}_{\mathrm{i}}$ é a média da variável $\mathrm{X}_{\mathrm{ij}}, \mathrm{S}_{\mathrm{i}}$ representa o desvio padrão da variável $X_{\mathrm{ij}}$, e $\mathrm{Y}_{\mathrm{ij}}$ é a representação da j-ésima observação da i-ésima variável transformada.

Como as variáveis classificatórias adotadas neste estudo são variáveis reais e, portanto, são mensuradas em uma escala de intervalo, adotou-se uma medida de distância com propriedades métricas, tendo a escolha recaído na distância euclidiana ao quadrado, por ser essa a mais utilizada (Everitt, 1993). O algoritmo de agrupamento empregado na definição dos agregados foi o método Ward (Hair Jr. et al., 2005).

Na definição do número de classes consideradas similares, tomou-se como base a técnica empírica descrita por Hair Jr. et al. (2005), a qual consiste em se analisar a diferença entre os níveis de fusão dos grupos no dendrograma e considerar a existência de um grupo de poços similares, quando ocorrer uma grande variação entre os seus níveis de fusão. Na definição da similaridade hidroquímica das águas subterrâneas do DIBAU, empregou-se a técnica de análise multivariada, em que o número de agrupamento depende do maior ou menor grau de homogeneidade que se deseja impor ao grupo formado (Andrade et al., 2008). O número de agrupamento foi definido no momento em que ocorre a primeira maior variação percentual entre os coeficientes de dois agrupamentos consecutivos (Hair Jr. et al., 2005). 
Os dados médios de cada parâmetro analisado dos respectivos grupos formados foram submetidos à análise de teste de média e confrontados pelo Teste $\mathrm{T}(\mathrm{p}<0,01)$, além da utilização de gráficos box-plot para auxiliar e facilitar a interpretação dos resultados de salinidades obtidos.

\section{RESULTADOS E DISCUSSÃO}

\section{Flutuação do lençol freático}

A ascensão do nível do lençol freático, coincidindo com a estação chuvosa, identifica que a precipitação pluviométrica determina a ascensão média do nível do lençol subterrâneo (Figura 2). Esta afirmativa fundamenta-se no fato de que após o término do período chuvoso, há uma redução do nível da água dos poços, com exceção dos poços P2 e P3 (área irrigada), nos quais o declínio ocorre de forma muito lenta (Figura 2). Comportamento semelhante foi encontrado por Fontes Júnior et al. (2012), avaliando a estabilidade temporal do nível potenciométrico da água subterrânea de um aquífero aluvial, no semiárido pernambucano. Observa-se, ainda, na Figura 2, que baixas precipitações não contribuem com a recarga do lençol freático, comportamento também observado em outros vales aluviais do semiárido (Burte et., 2005). Este fato confirma a ação da sazonalidade climática na dinâmica do nível do lençol freático.
Os poços inseridos na área irrigada, P3 e P4, apresentaram menores flutuações da lâmina do lençol freático (Figura 2), sendo sua dinâmica menos influenciada pelo regime pluviométrico, quando se compara com a dos poços da área de sequeiro, principalmente durante o Período 1. Esse comportamento é, possivelmente, decorrente das reduzidas alturas pluviométricas registradas nos anos de 2005 e 2006, eventos que contribuíram para a intensificação da prática de irrigação e a consequente recarga de água do lençol freático, advinda de lâminas excessivas, mesmo durante período de escassez de chuvas. Os níveis do lençol freático dos poços P3 e P4 (área irrigada), tendo-se como referência a lâmina de água medida em dezembro de 2003, apresentaram as maiores elevações absolutas. Os referidos poços registraram elevações do nível do lençol freático de 6,13 e 5,25 m, respectivamente, o que representa uma taxa de ascensão anual de 75 e 65 $\mathrm{cm}$, durante um período de oito anos (dezembro/2003 a julho/2011). Estas alterações confirmam a hipótese do emprego excessivo de lâminas de água na irrigação, pois verifica-se, claramente, que apenas P3, P4 e P5 (período 2) mantiveram níveis de água elevados, mesmo durante o período de estiagem do ano de 2010. Tem sido consenso de pesquisadores que grande parte da água aplicada por via de irrigação é drenada além do sistema radicular das culturas (Ersahin \& Karaman, 2001; Oster, 2006; Aquino

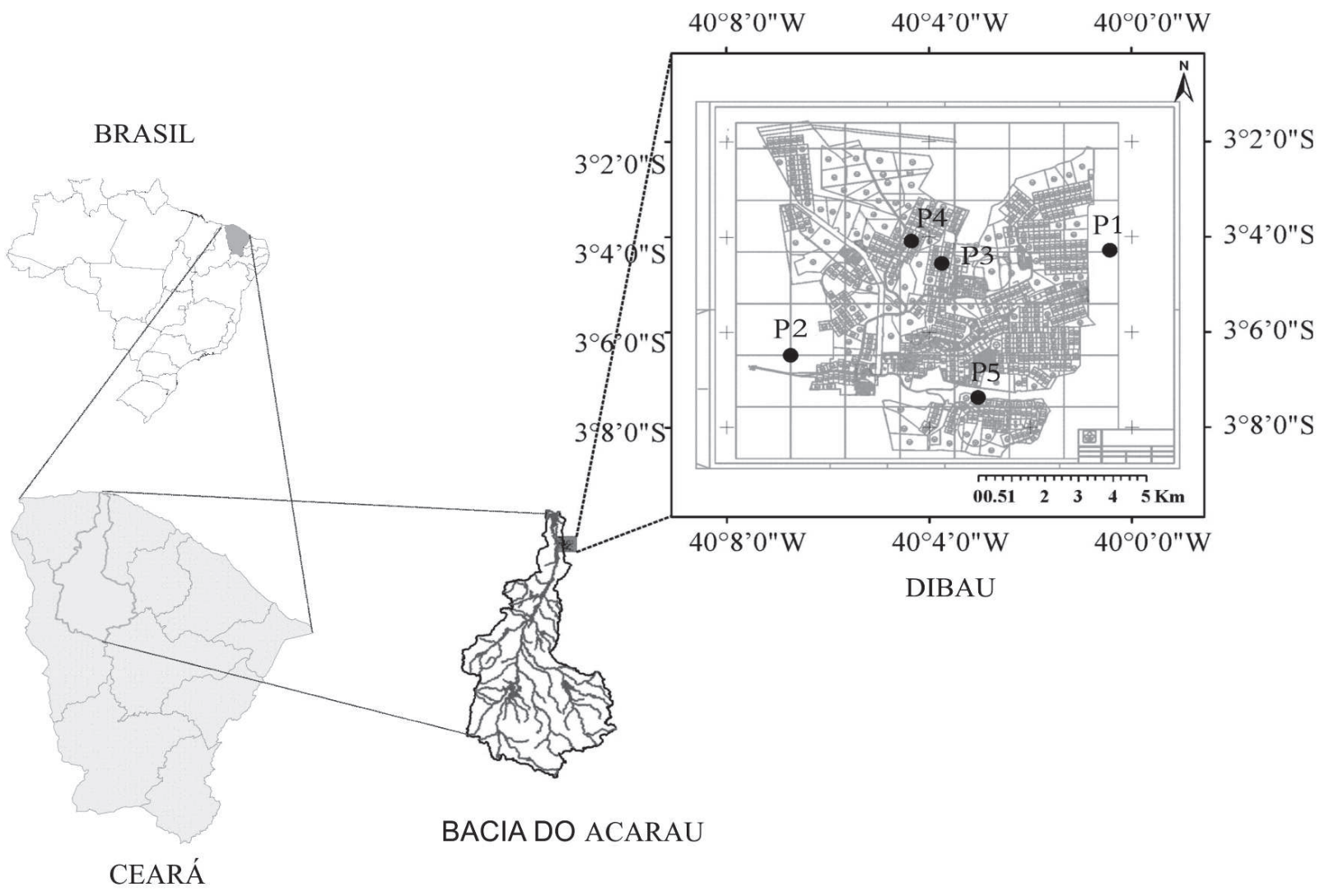

Figura 1: Localização do DIBAU na bacia hidrográfica do rio Acaraú, Ceará, Brasil.

Rev. Ceres, Viçosa, v. 63, n.5, p. 621-630, set/out, 2016 
et al., 2008), expressando um manejo inadequado da irrigação (frequência e lâmina de água); havendo, portanto, a necessidade de um ajuste no calendário das práticas de irrigação, no qual seja considerada a capacidade de retenção de água pelo solo.

Já os poços inseridos na área não irrigada, P1, P2 e P5 (período 1) apresentaram interdependência da sazonalidade climática, com variações ascendentes significativas, principalmente, durante as estações chuvosas de 2004 e de 2011 (Figura 2), além dos maiores declínios durante a estação seca, quando se compara com a dos poços inseridos na área irrigada. Para o ano de 2011, ocorreram registros da água do lençol subterrâneo do P5 (irrigado) a apenas 68 cm da superfície do solo.

Dentre os poços monitorados, o que apresenta as maiores elevações e depleções em curto espaço de tempo é o P2, dinâmica esta definida pelo regime hidrológico do rio Acaraú (anos de cheias alternados por anos de secas). Portanto, as maiores sensibilidades a oscilações do nível da água deste poço, quando se compara com a dos demais poços estudados, caracteriza a inversão do fluxo da recarga e descarga provindo das cheias e secas do rio Acaraú, visto que esse poço se encontra em área de influência direta do referido rio.

\section{Similaridade hidroquímica}

A primeira maior variação do percentual entre os coeficientes de dois agrupamentos consecutivos foi de $40,7 \%$ (312,557 - 222,273), a qual ocorreu na passagem da formação de 3 para 2 grupos (Tabela 1), deixando explícito que, para os dados analisados, o número mais adequado é de 3 (três) grupos.

A Tabela 2 apresenta o resultado de distribuição e agrupamento dos poços após efetivação do ponto de corte no dendrograma. A partir dela, fica demonstrado que o agrupamento da qualidade das águas subterrâneas dos poços no DIBAU foi definido pela variabilidade espacial das variáveis hidroquímicas analisadas (Andrade et al., 2008), não ocorrendo uma influência maior da variabilidade temporal.

A dinâmica das concentrações do sódio, do cloreto e do nitrato, nas águas subterrâneas, apresenta maior rela-

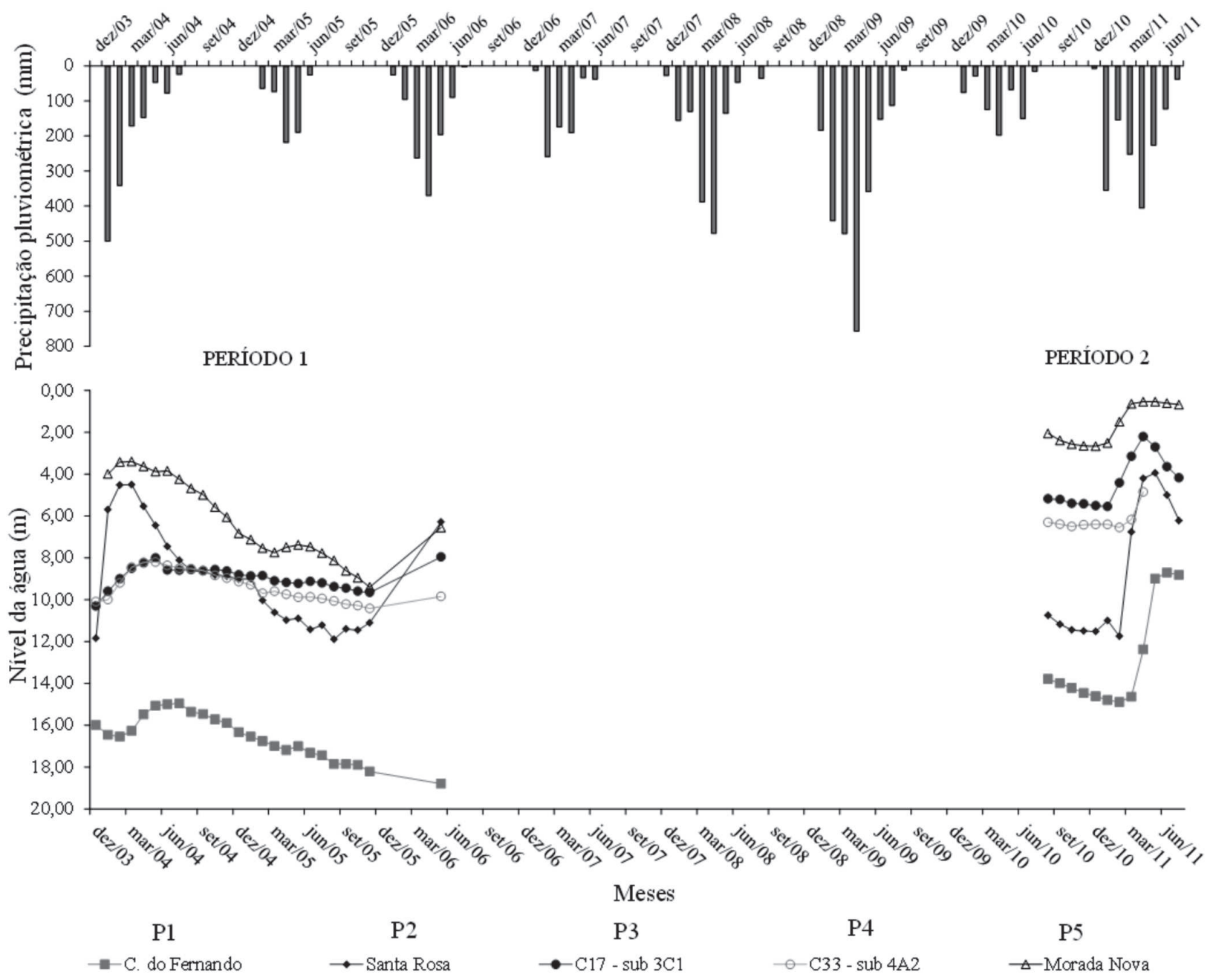

Figura 2: Precipitação pluviométrica e dinâmica da profundidade do lençol freático. 
ção com situações espaciais do que com as temporais; comportamento contrário ocorre nas águas superficiais (Vega et al., 1998; Palácio et al., 2008), deixando claro que além da precipitação natural, a intervenção antrópica, seja a partir da irrigação, seja da adubação, controla a dinâmica pontual da qualidade da água quanto aos íons em questão.

Analisando-se, ainda, a Tabela 2, observa-se que o Grupo 1 (G1) é constituído unicamente pelas águas provenientes dos poços da área não irrigada (P1, P2 e apenas quatro amostras do P5 (período 1), o que corresponde a $38 \%$ do total de amostras. As águas desses poços apresentaram os maiores teores de $\mathrm{Na}^{+}$e de $\mathrm{Cl}^{-}, 123,9 \mathrm{mg} \mathrm{L}^{-1} \mathrm{e}$ $253,2 \mathrm{mg} \mathrm{L}^{-1}$, respectivamente, diferindo estatisticamente das águas dos Grupo 2 (G2) e Grupo 3 (G3) (Tabela 3). Por se tratar de poços fora da área irrigada, infere-se que as maiores concentrações de $\mathrm{Na}^{+}$e de $\mathrm{Cl}^{-}$nesta área estão relacionados com os processos naturais geológicos e com a lixiviação de sais depositados na superfície do solo (Fontes Júnior et al., 2012). Outro fator que pode estar contribuindo para essa elevação é o acúmulo de sais provenien- tes das precipitações com aerossóis marinhos em sua composição (Souza et al., 2006), uma vez que o DIBAU situase a apenas $29 \mathrm{~km}$ da costa marítima (foz do rio Acaraú). Meireles (2007) observou um grande aumento da concentração de cloreto nas águas superficiais do açude Acaraú Mirim, o qual dista $61 \mathrm{~km}$ do DIBAU e $90 \mathrm{~km}$ da costa. Portanto, se aerossóis foram identificados em pontos mais distantes da costa, acredita-se no aporte de sódio e de cloreto às águas subterrâneas do DIBAU na forma de aerossóis.

Aliado a esse fato, tem-se que os solos em que os poços do Grupo 1 estão assentados são classificados como Argissolos distróficos e Neossolos Regolíticos de textura arenosa. De acordo com a Embrapa (2006), esses solos caracterizam-se por apresentar argila de atividade baixa ou argila de atividade alta, mas com saturação por base baixa, contribuindo, assim, para a ocorrência de grandes perdas das bases trocáveis do solo, por lixiviação, para o lençol freático. Apesar de o G1 apresentar as maiores concentrações de $\mathrm{Na}^{+}$, elas estão de acordo com os padrões para consumo humano estabelecidos pela Portaria 2914/2011

Tabela 1: Variação do coeficiente de aglomeração para a análise hierárquica de agrupamentos

\begin{tabular}{|c|c|c|c|c|}
\hline \multirow{2}{*}{$\begin{array}{l}\text { Número } \\
\text { de agrupamentos }\end{array}$} & \multicolumn{2}{|c|}{ Agrupamento combinado } & \multirow{2}{*}{ Coeficiente } & \multirow{2}{*}{$\begin{array}{c}\text { Variação percentual no coeficiente } \\
\text { para o próximo nível }\end{array}$} \\
\hline & Agrupamento 1 & Agrupamento 2 & & \\
\hline 180 & 59 & 60 & 0,0001 & \\
\hline 7 & 1 & 14 & 112,766 & 18,595 \\
\hline 6 & 41 & 66 & 133,735 & 15,892 \\
\hline 5 & 37 & 62 & 154,988 & 20,871 \\
\hline 4 & 41 & 133 & 187,336 & 18,649 \\
\hline 3 & 1 & 32 & 222,273 & 40,619 \\
\hline 2 & 37 & 41 & 312,557 & 71,809 \\
\hline 1 & 1 & 37 & 537,000 & \\
\hline
\end{tabular}

Tabela 2: Representação dos 3 (três) grupos distintos, obtidos no dendrograma, após processamento da análise multivariada

\begin{tabular}{|c|c|c|c|c|c|c|c|c|c|c|}
\hline \multicolumn{4}{|c|}{ GRUPO 1} & \multirow{2}{*}{$\begin{array}{r}\text { GRUPO } 2 \\
\text { P1-jul/11 }\end{array}$} & \multicolumn{6}{|c|}{ GRUPO 3} \\
\hline P1-dez/03 & P1-mai/05 & P1-mai/11 & P2-jan/05 & & P3-mar/04 & P3-ago/05 & P4-mai/04 & P4-out/05 & P5-jul/04 & P5-out/10 \\
\hline $\mathrm{P} 1-\mathrm{jan} / 04$ & P1-jun/05 & $P 1$-jun/11 & P2-fev/05 & P3-mai/06 & P3-abr/04 & P3-set/05 & P4-jun/04 & P4-nov/05 & P5-ago/04 & P5-nov/10 \\
\hline P1-fev/04 & P1-jul/05 & P3-dez/03 & P2-mar/05 & P3-abr/11 & P3-mai/04 & P3-out/05 & P4-jul/04 & P4-ago/10 & P5-set/04 & P5-dez/10 \\
\hline $\mathrm{P} 1-\mathrm{mar} / 04$ & $\mathrm{P} 1$-ago/05 & P3-jan/04 & $\mathrm{P} 2-\mathrm{abr} / 05$ & P3-mai/11 & P3-jun/04 & P3-ago/10 & P4-ago/04 & P4-set/10 & P5-out/04 & P5-jan/11 \\
\hline $\mathrm{Pl}$-abr/04 & $\mathrm{P} 1$-set/05 & P3-fev/04 & P2-mai/05 & P3-jun/11 & P3-jul/04 & $\mathrm{P} 3$-set/10 & P4-set/04 & $\mathrm{P} 4$-out/10 & P5-nov/04 & P5-fev/11 \\
\hline P1-mai/04 & $\mathrm{P} 1$-out/05 & P5-mai/04 & P2-jun/05 & P4-m & P3-ago/04 & P3-out/10 & P4-out/04 & P4-nov/10 & P5-dez/04 & P5-mar/11 \\
\hline P1-jun/04 & P1-nov/05 & P5-jan/05 & P2-jul/05 & P2-ja & P3-set/04 & P3-nov/10 & P4-nov/04 & P4-dez/10 & $\mathrm{P} 5-\mathrm{fev} / 05$ & P5-abr/11 \\
\hline P1-jul/04 & P1-mai/06 & P5-mai/05 & $\mathrm{P} 2$-ago/05 & P2-fe & P3-out/04 & P3-dez/10 & P4-dez/04 & P4-jan/11 & P5-mar/05 & \\
\hline P1-ago/04 & P1-ago/10 & P5-nov/05 & P2-set/05 & P2-mar/04 & P3-nov/04 & P3-jan/11 & P4-jan/05 & $\mathrm{P} 4-\mathrm{fev} / 11$ & $\mathrm{P} 5-\mathrm{abr} / 05$ & P5-jun/11 \\
\hline P1-set/04 & P1-set/10 & P2-dez/03 & P2-out/05 & P2-abr/11 & P3-dez/04 & P3-fev/11 & $\mathrm{P} 4-\mathrm{fev} / 05$ & P4-mar/11 & P5-jun/05 & P5-jul/11 \\
\hline P1-out/04 & P1-out/10 & P2-jun/04 & P2-nov/05 & P2-mai/11 & P3-jan/05 & P3-mar/11 & P4-mar/05 & P4-abri/11 & P5-jul/05 & $\mathrm{P} 2-\mathrm{abr} / 04$ \\
\hline P1-nov/04 & P1-nov/10 & P2-jul/04 & P2-mai/06 & & P3-fev/05 & P3-jul/11 & $\mathrm{P} 4-\mathrm{abr} / 05$ & P5-dez/03 & $\mathrm{P} 5$-ago/05 & P2-mai/04 \\
\hline P1-dez/04 & P1-dez/10 & P2-ago/04 & P2-ago/10 & & & P4-dez/03 & P4-mai/05 & & & P2-nov/10 \\
\hline P1-jan/05 & P1-jan/11 & P2-set/04 & $\mathrm{P} 2$-set/10 & & P3-abr/05 & P4-jan/04 & P4-jun/05 & P5-fev/04 & P5-out/05 & P2-jan/11 \\
\hline $\mathrm{P} 1-\mathrm{fev} / 05$ & P1-fev/11 & P2-out/04 & P2-out/10 & & P3-mai/05 & $\mathrm{P} 4-\mathrm{fev} / 04$ & P4-jul/05 & P5-mar/04 & P5-mai/06 & P2-fev/11 \\
\hline $\mathrm{P} 1-\mathrm{mar} / 05$ & P1-mar/11 & P2-nov/04 & P2-dez/10 & & P3-jun/05 & P4-mar/04 & P4-ago/05 & $\mathrm{P} 5-\mathrm{abr} / 04$ & P5-ago/10 & P2-mar/11 \\
\hline $\mathrm{P} 1-\mathrm{abr} / 05$ & $\mathrm{P} 1-\mathrm{abr} / 11$ & P2-dez/04 & P2-jul/11 & & P3-jul/05 & $\mathrm{P} 4-\mathrm{abr} / 04$ & P4-set/05 & P5-jun/04 & P5-set/10 & P2-jun/11 \\
\hline
\end{tabular}


do Ministério da Saúde, inferiores a $200 \mathrm{mg} \mathrm{L}^{-1}$, diferentemente das concentrações do íon cloreto, para o qual há restrições de uso para consumo humano, conforme essa legislação (>250 $\mathrm{mg} \mathrm{L}^{-1)}$ (Tabela 3).

O Grupo 2 é constituído por poços caracterizados por elevados teores de nitrato, $16,09 \mathrm{mg} \mathrm{L}^{-1}$, sempre superiores a $10 \mathrm{mg} \mathrm{L}^{-1}$, fora dos padrões estabelecidos para consumo humano, conforme Portaria 2914/2011 do Ministério da Saúde, diferindo estatisticamente dos demais grupos (Tabela 3). O referido grupo foi o que apresentou a menor quantidade de casos amostrais, apenas $6 \%$ do total (Tabela 2), representado pelos poços: P1 (julho/2011); P3 (maio/ 06 e período chuvoso de 2011); P4 (maio/06) e P2 (período chuvoso de 2004 e 2011).

As águas dos poços supramencionados apresentaram valores elevados de nitrato durante a estação chuvosa, evidenciando que a lixiviação ocorre principalmente pela ação das chuvas. Este comportamento confirma que a adição de nitrato às águas subterrâneas dos poços da área irrigada decorre da lixiviação de nutrientes, provenientes de fertilizantes nitrogenados empregados excessivamente na agricultura irrigada, como já identificado por outros pesquisadores (Feng et al., 2005; Oster, 2006; Andrade et al., 2009; Chen et al., 2010).

A contaminação das águas subterrâneas com íons de nitrato está relacionada com o processo de lixiviação, por causa de sua alta mobilidade e estabilidade nos sistemas aeróbios de águas subterrâneas e, ao longo do tempo, pode haver considerável incremento dos teores de nitrato das águas do lençol freático (Varnier \& Hirata, 2002; Scanlon et al., 2010).

O Grupo 3 é constituído por águas coletadas nos poços da área irrigada (P3, P4 e P5), independentemente da estação anual amostrada (seca ou chuvosa) (Tabela 2). As menores concentrações dos íons $\mathrm{Na}^{+}$e $\mathrm{Cl}^{-}$das águas do G3 (Tabela 3) estão, possivelmente, correlacionadas com a maior diluição desses íons, decorrente de um acréscimo extra de lâmina d'água proveniente da prática de irrigação, comportamento já evidenciado na Figura 2.
A Figura 3 justifica a afirmativa supramencionada; nela se observa que os valores da mediana do nível do lençol freático dos poços situados na área irrigada, Grupos 2 e 3 , apresentaram-se sempre abaixo dos encontrados no Grupo 1, caracterizando uma menor profundidade do nível da água do lençol freático, estando, assim, mais próximos da superfície do solo, principalmente para o período monitorado 2, independentemente da estação climática. E como, quanto ao Grupo 2, tratava-se de amostras da época chuvosa, mesmo com poços situados em áreas não irrigadas, a exemplo de apenas uma amostra do P1 e várias do P2, este sofreu influência da recarga do rio Acaraú, aproximando-se, portanto, do nível de água do Grupo 3, influenciado também pelas lâminas excessivas de irrigação.

Os níveis das águas do lençol freático que compõem o Grupo 1, principalmente no período 1, apresentaram maior amplitude interquartil, mostrando maior dinâmica dos níveis das águas freáticas, quando comparados com os níveis dos poços inseridos na área irrigada. Este comportamento define a maior influência da sazonalidade climática sobre os poços que compõem o Grupo 1 (área de sequeiro).

As maiores concentrações de nitrato foram registradas em poços do Grupo 2, no período 2, verificando-se grandes acréscimos desse elemento, nas estações chuvosas de 2004 e 2011 (Figura 4), provavelmente, por lavagem de fontes de fertilizantes nitrogenados lixiviados do perfil do solo.

Esse comportamento já foi observado em diferentes partes do mundo (Burte et al., 2005; Feng et al., 2005; Chen et al., 2010; Nunes et al., 2012) e expressa a necessidade de mudanças nos manejos da irrigação.

Ademais, é importante destacar que durante a estação chuvosa do período 2 (janeiro a maio de 2011) observa-se maior amplitude interquartil em todos os agrupamentos formados, principalmente no agrupamento 2, mostrando a lixiviação intensa e o aporte desse elemento à água do lençol freático, percolado pelas águas das chuvas. De acordo com Andrade et al. (2009), anualmente, eram adicionados ao solo da área irrigada, em média, $80 \mathrm{~kg} \mathrm{ha}^{-1}$ de nitro-

Tabela 3: Valores médios (erro padrão), mínimos e máximos referente ao $\mathrm{Na}^{+}, \mathrm{Cl}^{-} \mathrm{e} \mathrm{NO}_{3}^{-}$, em cada grupo de poços subterrâneos do DIBAU

\begin{tabular}{|c|c|c|c|c|}
\hline & Parâmetros Descritivos & $\mathrm{Na}^{+}\left(\mathbf{m g L}^{-1}\right)$ & $\mathrm{Cl}^{-}\left(\mathrm{mgL}^{-1}\right)$ & $\mathrm{NO}_{3}^{-}\left(\mathrm{mgL}^{-1}\right)$ \\
\hline \multirow{3}{*}{ G 1} & Média & $123,9(3,7) \mathrm{A}$ & $253,2(9,5) \mathrm{A}$ & $2,0(0,2) \mathrm{C}$ \\
\hline & Mínimo & 116,5 & 235,2 & 1,7 \\
\hline & Maximo & 131,6 & 273,2 & 2,4 \\
\hline \multirow{3}{*}{ G 2} & Média & $53,6(9,4)$ B & $135,7(16,5) \mathrm{B}$ & $16,0(1,8) \mathrm{A}$ \\
\hline & Mínimo & 40,8 & 105,4 & 12,6 \\
\hline & Maximo & 75,9 & 172,2 & 19,8 \\
\hline \multirow{3}{*}{ G 3} & Média & $57,9(2,7) \mathrm{B}$ & $101,6(5,0) \mathrm{B}$ & $3,9(0,2) \quad \mathrm{B}$ \\
\hline & Mínimo & 52,6 & 91,4 & 3,5 \\
\hline & Maximo & 63,6 & 116,6 & 4,5 \\
\hline
\end{tabular}


gênio, na forma de ureia, $130 \mathrm{~kg} \mathrm{ha}^{-1} \mathrm{em}$ esterco bovino e $300 \mathrm{~kg} \mathrm{ha}^{-1}$ de nitrogênio na forma esterco de galinha. Portanto, com a chegada da estação chuvosa, esses sais nitrogenados são potencialmente lixiviados e pouco retidos, em decorrência da textura arenosa do solo, para as camadas mais profundas, proporcionando rapidamente seu acúmulo na água do lençol freático. Portanto, dependendo da cultura agrícola, mesmo que tenha havido aplica- ções regulares de fertilizantes, em função da textura arenosa do solo, a retenção dos íons é reduzida e a lixiviação para maiores profundidades é potencializada.

Em decorrência do pequeno número de unidades amostrais encontrado no Grupo 2, não se obtiveram dados suficientes para representação do Box plot no período 2, estação seca, tanto para os níveis do lençol freático (Figura 3) quanto para o nitrato (Figura 4).

\section{PERIODOS}

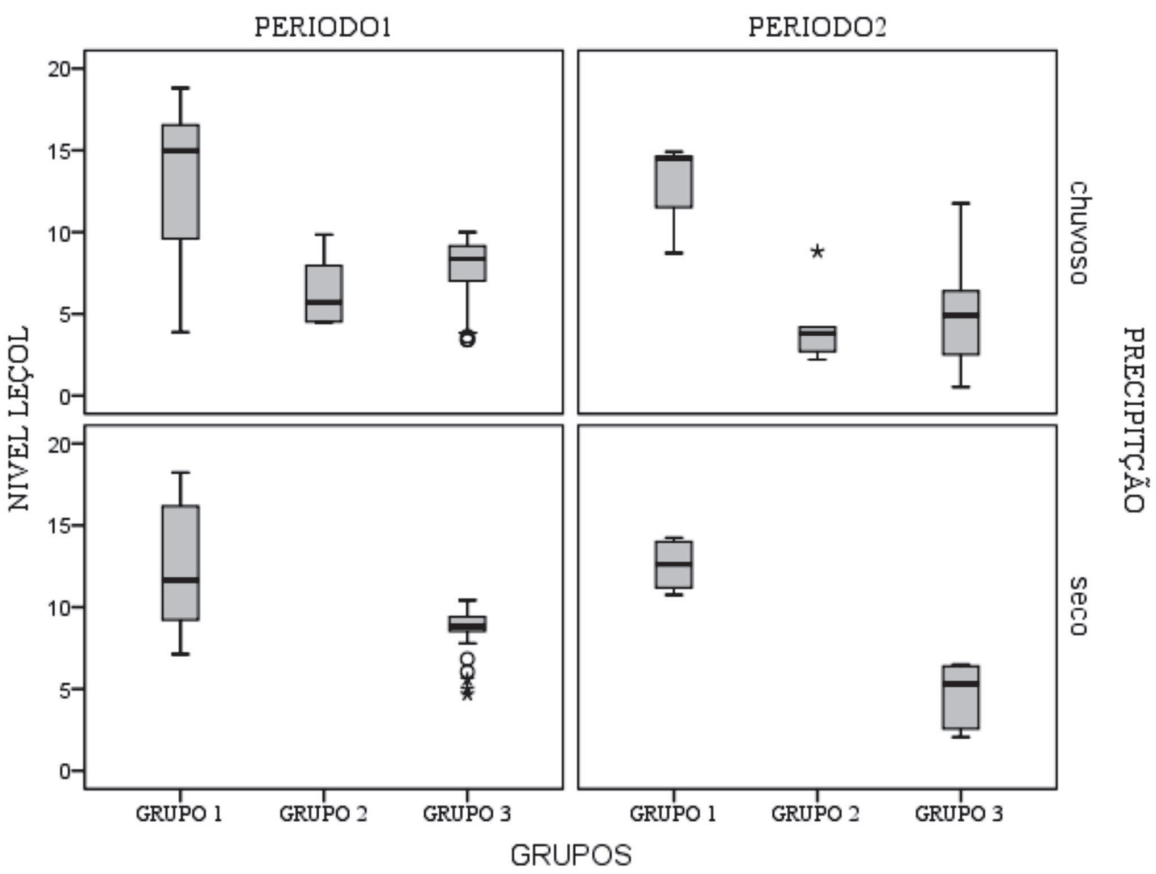

Figura 3: Nível do lençol freático no DIBAU, durante os períodos estudados, para as estações chuvosa e seca.

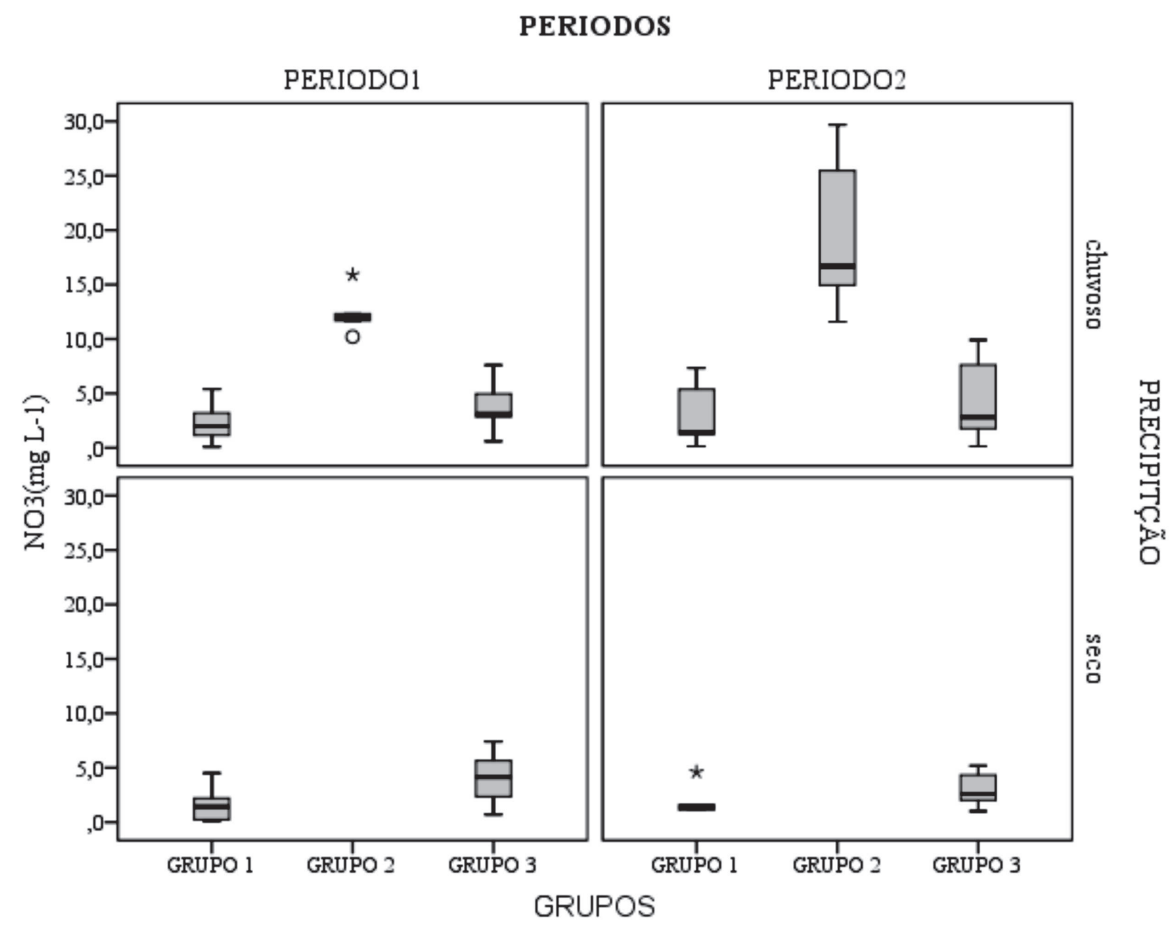

Figura 4: Concentração do nitrato $\left(\mathrm{NO}_{3}^{-}\right)$, durante os períodos estudados, para as estações chuvosa e seca. 


\section{CONCLUSÕES}

As menores flutuações sazonais do nível do lençol freático ocorreram nos poços inseridos na área irrigada, mostrando excedentes de lâminas de irrigação e recarga desses poços durante a estação de estiagem.

No tocante às variáveis analisadas, $\mathrm{Na}^{+}, \mathrm{Cl}^{-}$e $\mathrm{NO}_{3}^{-}$, independentemente da estação sazonal anual, houve diferenças significativas entre a qualidade das águas dos poços inseridos na área irrigada e a dos de sequeiro.

As águas dos poços da área de sequeiro apresentaram as maiores concentrações dos íons $\mathrm{Na}^{+}$e $\mathrm{Cl}^{-}$, quando se comparam com as dos poços da área irrigada.

As preocupantes concentrações dos teores de $\mathrm{NO}_{3}{ }^{-}$nas águas dos poços influenciados pela agricultura irrigada excedem o limite máximo estabelecido pela Portaria 2914/2011.

\section{REFERÊNCIAS}

Alaburda J \& Nishihara L (1998) Presença de compostos de nitrogênio em águas de poços. Revista de Saúde Pública, 32:160-165.

Andrade EM, Aquino DN, Crisostomo LA, Rodrigues JO \& Lopes FB (2009) Impacto da lixiviação de nitrato e cloreto no lençol freático sob condições de cultivo irrigado. Revista Ciência Rural, 39:88-95.

Andrade EM, Palácio HA, Souza IH, Leão RAO \& Guerreiro MJ (2008) Land use effects in groundwater composition of an alluvial aquifer (Trussu River, Brazil) by multivariate techniques. Environmental Research, 106:170-177.

Aquino DN, Andrade EM, Lopes FB, Teixeira AS \& Crisostomo LA (2008) Impacto do manejo da irrigação sobre os recursos solo e água. Revista Ciência Agronômica, 39:225-232.

Alves NNL (2006) Proposta de elaboração de um sistema de informações geográficas para programação da irrigação parcelar do perímetro irrigado do Baixo Acaraú. Monografia. Universidade Federal do Ceará, Fortaleza. 72p.

Araújo SCS (2005) Modelos de simulação baseados em raciocínio qualitativo para avaliação da qualidade da água em bacias hidrográficas. Tese de Doutorado. Universidade de Brasília, Brasília. 218p.

Baba A \& Tayfur G (2011) Groundwater contamination and its effect on health in Turkey. Environmental Monitoring and Assessment, 183:77-94.

Brown L, Flavin C \& French H (2000) Estado do mundo 2000. Salvador, UMA Editora. 288p.

Burte J, Coudrain A, Frischkorn H, Chaffaut I \& Kosuth P (2005) Impacts Anthropiques sur Les Termes du Bilan Hydrologique d'un Aquifére Alluvial Dans Le Nordeste Semi-Aride, Brasil. Hidrological Sciences Journal, 50:001-110.

Chen S, Wu W, Hu K \& Li W (2010) The effects of land use change and irrigation water resource on nitrate contamination in shallow groundwater at county scale. Ecological Complexity, 7:131-138.

EMBRAPA - Empresa Brasileira de Pesquisa Agropecuária (2013) Sistema Brasileiro de Classificação de Solos. $3^{\text {a }}$ ed. Brasília, Embrapa Solos. 353p.

Ersahin S \& Karaman MR (2001) Estimating potential nitrate leaching in nitrogen fertilized and irrigated tomato using the computer model NLEAP. Agricultural Water Management, 51:01-12.
Feng ZZ, Wang XK \& Feng ZW (2005) Soil N and salinity leaching after the autumn irrigation and its impact on groundwater in Hetao Irrigation District, China. Agricultural Water Management, 71:131-143.

Fontes Júnior VP, Montenegro AAA, Montenegro SMGL \& Santos TEM (2012) Estabilidade temporal da potenciometria e da salinidade em vale aluvial no semiárido de Pernambuco. Revista Brasileira de Engenharia Agrícola e Ambiental, 16:1188-1197.

Hair Jr. JF, Anderson RE, Tatham RL \& Black WC (2005) Análise Multivariada de Dados. Porto Alegre, Bookman. 593p.

Khaw KT \& Barrett CE (1987) Dietary potassium and stroke associated mortality. New England Journal of Medicine, 316:235240 .

Köppen NW (1918) Climatologia: com um estudio de los climas de la Tierra. México, Fundo de Cultura Econômica. 478p.

Manning AH, Solomon DK \& Thiros AS (2005) He age data in assessing the susceptibility of wells to contamination. Ground Water, 43:353-367.

Matias Filho J, Costa RNT, Menezes JAL, Loiola ML, Meireles M \& Pereira ALS (2001) Estudos e Pesquisas para avaliação de riscos potenciais de drenagem e/ou salinidade na área prioritária do projeto de irrigação Baixo Acaraú. Fortaleza, UFC. 27p. (Relatório Técnico, 1).

Meireles ACM (2007) Dinâmica qualitativa das águas superficiais da bacia do Acaraú e uma proposta de classificação para fins de irrigação. Tese de Doutorado. Universidade Federal do Ceará, Fortaleza, 180p.

Molina MDB, Cunha RS, Herkenhoff LF \& Mill JG (2003) Hipertensão arterial e consumo de sal em população urbana. Revista de Saúde Pública, 37:743-750.

Moore BK, Ekwurzel B, Esser KB, Hudson GB \& Moran JE (2006) Sources of groundwater nitrate revealed using residence time and isotope methods. Applied Geochemistry, 21:1016-1029.

Nunes MLA, Gomes JB, Webler AD, Andrade LR \& Marchetto M (2012) Comprometimento da qualidade da água subterrânea por nitratos. Nucleus, 9:63-72.

Osenbrück K, Fiedler S, Knöller K, Weise SM, Sültenfuß J, Oster H \& Strauch G (2006) Timescales and development of groundwater pollution by nitrate in drinking water wells of the Jahna-Aue, Saxonia, Germany. Water Resources Research, 42:3259-3270.

Oster H (2006) Tracing of contaminated shallow groundwater in a deep aquifer system, Germany. In: Oster H (Ed.) Use of Chlorofluorocarbons in hydrology: A guidebook. Vienna, International Atomic Energy Agency. 277p.

Palácio HAQ, Andrade EM, Crisóstomo LA, Teixeira AS \& Souza IH (2008) Selection of the determinates Trussu River Water quality factors using multivariable analysis. Geographia Technica, 5:74-81.

Ramos LA, Cavalheiro CCS \& Cavalheiro ETG (2006) Determinação de nitrito em águas utilizando extrato de flores. Química Nova, 29:1114-1120.

Richards LA (1954) Diagnosis and improvement of saline and alkali soils. Washington, United State Departament of Agriculture. 1960p.

Scanlon BR, Reedy RC, Gates JB \& Gowda PH (2010) Impact of agroecosystems on groundwater resources in the Central High Plains, USA, Agriculture. Ecosystems and Environment, 139:700-713.

Souza PA, Mello WZ \& Maldonato J (2006) Composição química e aporte atmosférico na Ilha Grande, RJ. Quimica Nova, 29:471476 . 
Tundisi JG (2003) Água no século XXI: Enfrentando a Escassez. São Carlos, RIMA. 248p.

Varnier C \& Hirata R (2002) Contaminação da água subterrânea por nitrato no parque ecológico do Tietê - São Paulo, Brasil. Revista Águas Subterrâneas, 16:097-104.

Vega M, Pardo R, Barrado E \& Deban L (1998) Assessement of seasonal and polluting effects on the quality of river water by exploratory data analysis. Water Research, 32:3581-3592.
Withers PJA, May L, Jarvie HP, Jordan P, Doody D, Foy RH, Bechmann M, Bechmann S, Cooksley RD \& Deal ND (2012) Nutrient emissions to water from septic tank systems in rural catchments: Uncertainties and implications for policy. Environmentalscience \& Policy, 24:71-82. 